\title{
ARTIGO CIENTÍFICO \\ Avaliação dos municípios do Nordeste brasileiro pelos objetivos do desenvolvimento sustentável e o triple bottom line
}

\section{Evaluation of municipalities in the Brazilian northeastern according to sustainable development objectives and the triple bottom line}

\author{
Ronaldo Ferreira da Silva ${ }^{1}$, Leonardo de Lima Moura ${ }^{2}$, Luiz Octávio Gavião ${ }^{3}$, Gilson Brito Alves Lima ${ }^{4}$, Edison Dausacker \\ Bidone 5
}

Resumo: Os objetivos do desenvolvimento sustentável (ODS) da Organização das Nações Unidas buscam inserir o bemestar, a redução da pobreza e a utilização eficiente dos recursos naturais na noção de desenvolvimento econômico. O Triple Bottom Line (TBL) é um modelo passível de ser parametrizado que propõe o dimensionamento da sustentabilidade nas dimensões social, econômica e ambiental e que pode ser aplicado na avaliação de organizações e municípios. Objetivou-se estabelecer um ranking de quinze municípios da região Nordeste pelo seu nível de sustentabilidade, utilizando dezesseis indicadores de ações, atividades e políticas públicas alinhadas com os ODS e sob a ótica do TBL. Cada município foi avaliado em relação a todos os indicadores pela Composição Probabilística de Preferências $(\mathrm{CPP})$, um método multicritério de apoio à decisão. Os resultados demonstraram que tanto a perspectiva social quanto a econômica, envolve contrapartidas ambientais que podem comprometer a sustentabilidade dos municípios e que o bom desempenho em apenas uma dimensão não é suficiente para expressar a sustentabilidade, reforçando a importância da abordagem do desenvolvimento sustentável no crescimento econômico.

Palavras-chave: Economia Regional; Recursos hídricos; Sustentabilidade

\begin{abstract}
The objectives of the sustainable development of the United Nations seek to integrate well-being, poverty reduction and efficient use of natural resources into the notion of economic development. The Triple Bottom Line (TBL) is a parameterized model that proposes the dimensioning of sustainability in the social, economic and environmental dimensions and that can be applied in the evaluation of organizations and municipalities. This article establishes a ranking of fifteen municipalities in the Northeast region for their level of sustainability, using sixteen indicators of actions, activities and public policies aligned with the ODS and from the perspective of the TBL. Each municipality was evaluated in relation to all indicators by the Probabilistic Composition of Preferences (CPP), a multicriteria decision support method. The results demonstrated that the social and economic perspectives involve environmental impacts that can compromise the sustainability of municipalities and that good performance in only one dimension is not enough to express sustainability, reinforcing the importance of sustainable development approach to economic growth.
\end{abstract}

Key words: Regional Economics; Sustainability; Water resources

\footnotetext{
*Autor para correspondência

Recebido para publicação em 20/07/2017; aprovado em 28/09/2017

${ }^{1}$ Doutorando do Programa de Pós Graduação em Sistemas de Gestão Sustentáveis. Universidade Federal Fluminense. ronaldorubano@gmail.com

${ }^{2}$ Doutorando do Programa de Pós Graduação em Engenharia Civil. Universidade Federal do Rio de Janeiro. mouraventura@uol.com.br

${ }^{3}$ Doutorando do Programa de Pós Graduação em Engenharia de Produção. Universidade Federal Fluminense. luiz.gaviao67@ gmail.com

${ }^{4}$ Professor do Programa de Pós Graduação em Sistemas de Gestão Sustentáveis. Universidade Federal Fluminense. glima@id.uff.br

${ }^{5}$ Professor do Programa de Pós Graduação em Sistemas de Gestão Sustentáveis. Universidade Federal Fluminense. ebidone@ yahoo.com.br
} 


\section{INTRODUÇÃO}

Em 2015, a Organização das Nações Unidas (ONU) adotou os Objetivos de Desenvolvimento Sustentável (ODS). Trata-se de uma agenda para orientar as políticas nacionais e a cooperação internacional buscando a erradicação da pobreza, a ampliação do acesso à saúde e à segurança alimentar, a promoção do crescimento econômico e a redução da degradação ambiental. Constitui-se de objetivos e metas universais que equilibram as três dimensões do desenvolvimento sustentável (econômica, social e ambiental) e envolvem os países desenvolvidos e os em desenvolvimento (ONU, 2016a).

Neste contexto, o conceito de desenvolvimento que tradicionalmente esteve associado ao crescimento econômico, passa a abranger também a redução da pobreza, a qualidade de vida e a preservação do ambiente. Entretanto, há uma insuficiência de indicadores, além do poder de compra e do crescimento da renda, para a avaliação do nível de desenvolvimento (KAGEYAMA; HOFFMANN, 2006).

No mesmo sentido, o Triple Bottom Line, conceito desenvolvido por John Elkington em 1997, propõe o dimensionamento da sustentabilidade não apenas na dimensão econômica, mas também na perspectiva social que se refere à preocupação com o bem-estar humano e na perspectiva ambiental que considera a utilização racional dos recursos naturais. Como foi aceito mundialmente, é um modelo passível de ser parametrizado e aplicado em avaliações de desempenho da sustentabilidade (JUNQUEIRA et al., 2011; MACEDO et al., 2011).

Embora tenha apresentado em 2016 o nono maior Produto Interno Bruto (PIB) do mundo (BANCO MUNDIAL, 2016), o Brasil ocupava em 2015 a 79 ${ }^{a}$ posição no ranking mundial do Índice de Desenvolvimento Humano (ONU, 2016b). Nos últimos anos, o PIB tem sido mantido pelo desenvolvimento do agronegócio. Entretanto, os avanços no campo têm impacto sobre o meio ambiente e, além disso, a variação do clima fará com que, em alguns anos e em determinadas regiões, haja alterações na atividade agrícola. Este cenário impõe a utilização sustentável dos recursos naturais para a manutenção da capacidade produtiva da agropecuária (BARROS, 2014).

No Nordeste brasileiro, quase metade da população economicamente ativa está ocupada nas atividades agropecuárias recebendo até um salário mínimo, contra a média nacional que é de $26 \%$. Nesta região a agricultura familiar vem sendo substituída pelo agronegócio, com o avanço da ovino-caprinocultura, do crescimento de lavouras permanentes e da expansão da área cultivada com a incorporação de novos polos agrícolas. Entretanto, esta mudança não ocorre de modo homogêneo em função das diferenças de fertilidade do solo, disponibilidade de água, clima, localização e tecnologia (PEDROSO, 2014).

Nesta conjuntura, a agricultura continua sendo considerada uma atividade relevante para a economia do Nordeste brasileiro, porém, apresenta elevada dependência dos recursos hídricos, historicamente escassos na região. A atividade extensiva utiliza modelos que favorecem a monocultura e que requerem uma maior disponibilidade hídrica em função da maximização da produção. O modelo de subsistência também utiliza a irrigação, porém, face à escassez deste recurso, principalmente no semiárido, a utilização de águas residuárias tem sido uma alternativa cada vez mais frequente (BARROS, 2014; SILVA, et al. 2014; MEDEIROS, et al., 2015; ALBUQUERQUE JÚNIOR, et al., 2016).

A necessidade de água para irrigação também aumentou a preocupação com a qualidade das águas superficiais. O lançamento de efluentes contendo diversas substâncias em corpos d'água encarece o tratamento deste recurso para o abastecimento público, fazendo gerar situações de escassez de água de qualidade em áreas com abundantes recursos hídricos (FERREIRA, et al., 2014; SOUSA, et al., 2014; ANDRADE, et al., 2015; CHAVES, et al., 2015).

Outra causa da crescente escassez de água é o desenvolvimento econômico. A introdução de políticas públicas que aumentaram a renda das famílias contribuiu para o crescimento das cidades médias da região e dos setores de do comércio e dos serviços, gerando empregos formais, alterando a dinâmica do mercado de trabalho local e aumentando a taxa de ocupação da população economicamente ativa. Por outro lado, embora o desenvolvimento seja imprescindível para a redução da pobreza, dependendo do modelo adotado, pode resultar em impactos ambientais (ARAÚJO, 2014).

Além das atividades econômicas, os serviços públicos também geram estes impactos. A ampliação do acesso aos serviços de saúde, por exemplo, quando desacompanhada dos devidos investimentos em tratamentos de efluentes também pode contribuir para piorar ou encarecer o abastecimento de água de qualidade devido ao despejo dos resíduos destes serviços nos mananciais. Neste cenário, é relevante a percepção do desenvolvimento dos municípios sob a ótica da sustentabilidade, avaliando-se os aspectos econômicos, sociais e ambientais (MOTA et al., 2014; PROQUE, 2014; SILVA, 2016).

Um dos principais poluentes dos recursos hídricos são as substâncias químicas, como por exemplo, os fármacos. Estas substâncias, após a sua administração, são apenas parcialmente absorvidas pelo organismo e o restante é inserido no ambiente após sua excreção pelos pacientes nos hospitais e residências e pelos animais, principalmente em áreas de atividade agropecuária (KÜMMERER et al., 2016).

No Brasil, o problema é agravado porque a maioria dos serviços de saúde não realiza tratamento prévio em seus efluentes, lançando os despejos na rede de esgotos. Além disso, o país concentra um dos maiores rebanhos do mundo de animais destinados ao abate que utilizam fármacos regularmente (GALLO et al., 2012; GAVIÃO et al., 2016; SILVA, 2016).

Dentre as diversas classes de fármacos, destacam-se os antineoplásicos, utilizados no tratamento do câncer. Sua presença no ambiente aquático pode trazer graves danos ao ecossistema e pode vir a representar um passivo ambiental decorrente de um maior acesso da população ao tratamento desta patologia, pois nem sempre são sensíveis aos processos de degradação nas estações de tratamento de esgoto (BOOKER et. al., 2014; PARRELLA et al., 2014; MOURA et. al., 2015; KÜMMERER et al., 2016).

$\mathrm{O}$ atendimento aos ODS vem evoluindo na região Nordeste em função do incremento da atividade econômica e do acesso aos serviços de saúde e saneamento. Objetivou-se demonstrar, sob a ótica do Triple Bottom Line (TBL), que ações, atividades e políticas públicas alinhadas com os ODS na perspectiva social e econômica e ambientais podem 
comprometer a sustentabilidade de 15 municípios da Região Nordeste do Brasil.

\section{MATERIAL E MÉTODOS}

Trata-se de um estudo quali-quantitativo no qual os indicadores de todos os municípios, no período compreendido entre 2011 e 2015, foram coletados através de pesquisa bibliográfica e documental e avaliados pela Composição Probabilística de Preferências (CPP), um método de apoio multicritério à decisão para estabelecer um ranking final de sustentabilidade.

A amostragem dos municípios analisados foi constituída de quinze municípios localizados nos estados da região Nordeste do país, não situados no litoral e que disponibilizassem unidades de atendimento oncológico pelo Sistema Único de Saúde (SUS) e acesso aos dados referentes aos demais critérios do estudo. Dados incompletos dos órgãos consultados determinaram a exclusão de outros municípios da pesquisa. Da Bahia (BA), foram escolhidas as cidades de Feira de Santana, Itabuna, Juazeiro, Teixeira de Freitas e Vitória da Conquista; de Alagoas (AL), o município de Arapiraca; de Pernambuco (PE), as cidades de Caruaru, Garanhuns e Petrolina; do Rio Grande do Norte (RN) a cidade de Mossoró; da Paraíba (PB), o município de Campina Grande; do Ceará (CE), as cidades de Barbalha e Sobral; do Piauí (PI), a cidade de Teresina e do Maranhão (MA), a cidade de Imperatriz.

Para a avaliação dos municípios em relação às dimensões social, econômica e ambiental do TBL, foram definidos critérios aderentes aos objetivos do desenvolvimento sustentável da ONU. Foram escolhidos critérios que direta ou indiretamente expressassem o atendimento a estes objetivos e cuja disponibilidade de dados permitisse a elaboração do trabalho. Cada critério, expresso na tabela 1, tem uma correspondência com um ou mais objetivos do desenvolvimento sustentável.

Tabela 1. Critérios adotados e sua correspondência com os Objetivos do Desenvolvimento Sustentável.

\begin{tabular}{|c|c|c|c|c|c|c|c|c|c|c|c|}
\hline \multicolumn{4}{|c|}{ DIMENSÃO SOCIAL } & \multicolumn{4}{|c|}{ DIMENSÃO ECONÔMICA } & \multirow{2}{*}{\multicolumn{3}{|c|}{$\begin{array}{l}\text { DIMENSÃO AMBIENTAL } \\
\text { RECURSOS HÍDRICOS }\end{array}$}} & \multirow[b]{3}{*}{ ODS } \\
\hline \multicolumn{2}{|c|}{ SANEAMENTO } & \multirow{2}{*}{$\begin{array}{l}\text { SAÚDE } \\
\text { CRITÉRIO }\end{array}$} & \multirow[b]{2}{*}{ ODS } & \multicolumn{2}{|c|}{$\begin{array}{l}\text { EMPREGO E } \\
\text { RENDA }\end{array}$} & \multicolumn{2}{|c|}{$\begin{array}{l}\text { ATIVIDADES } \\
\text { ECONÔMICAS }\end{array}$} & & & & \\
\hline CRITÉRIO & ODS & & & CRITÉRIO & ODS & CRITÉRIO & ODS & CRITÉRIO & ODS & CRITÉRIO & \\
\hline $\begin{array}{l}\text { Índice de } \\
\text { atendimento } \\
\text { total de esgoto }\end{array}$ & $\begin{array}{l}6.1 \\
6.4 \\
6 . \mathrm{a} \\
6 . \mathrm{b}\end{array}$ & $\begin{array}{l}\text { Taxa de } \\
\text { Mortalidade } \\
\text { infantil }\end{array}$ & 3.2 & $\begin{array}{l}\text { Renda } \\
\text { média }\end{array}$ & $\begin{array}{c}1.1 \\
1.2 \\
10.1 \\
10.4\end{array}$ & PIB & $\begin{array}{l}8.2 \\
8.3 \\
8.4\end{array}$ & $\begin{array}{l}\text { Rebanho } \\
\text { bovino }\end{array}$ & $\begin{array}{c}6.3 \\
12.4\end{array}$ & População & $\begin{array}{c}6.3 \\
12.4\end{array}$ \\
\hline $\begin{array}{l}\text { Índice de } \\
\text { atendimento } \\
\text { total de água }\end{array}$ & $\begin{array}{l}6.2 \\
6 . a \\
6 . b\end{array}$ & $\begin{array}{l}\text { Taxa de } \\
\text { Mortalidade } \\
\text { por } \\
\text { atendimento } \\
\text { hospitalar }\end{array}$ & 3.4 & $\begin{array}{l}\text { Taxa de } \\
\text { ocupação }\end{array}$ & 8.3 & $\begin{array}{l}\text { Produção } \\
\text { pecuária }\end{array}$ & 2.4 & $\begin{array}{l}\text { Total de } \\
\text { Pacientes } \\
\text { oncológicos } \\
\text { atendidos }\end{array}$ & $\begin{array}{c}6.3 \\
12.4\end{array}$ & $\begin{array}{l}\text { Área } \\
\text { cultivada }\end{array}$ & $\begin{array}{c}6.5 \\
6.6 \\
12.4\end{array}$ \\
\hline & & $\begin{array}{l}\text { Índice de } \\
\text { atendimento } \\
\text { hospitalar }\end{array}$ & $\begin{array}{l}3.8 \\
3 . \mathrm{c}\end{array}$ & & & $\begin{array}{l}\text { Produção } \\
\text { agrícola }\end{array}$ & 2.4 & $\begin{array}{l}\text { Quantidade } \\
\text { de hospitais }\end{array}$ & $\begin{array}{c}6.3 \\
12.4\end{array}$ & $\begin{array}{l}\text { Índice de } \\
\text { esgoto } \\
\text { tratado }\end{array}$ & 6.6 \\
\hline
\end{tabular}

ODS: Objetivos do Desenvolvimento Sustentável

Para a avaliação da sustentabilidade dos municípios em relação à dimensão social, foram utilizados critérios de saúde e saneamento como taxa de mortalidade infantil, de óbitos por atendimento hospitalar, quantidade de estabelecimentos hospitalares por habitante e população atendida por esgotamento sanitário e água potável. Quanto menores os dois primeiros e maiores os três últimos, melhor o desempenho do município na dimensão social.

Para a avaliação da sustentabilidade dos municípios em relação à dimensão econômica, utilizaram-se critérios de emprego e renda como a população ocupada e a renda média, além da atividade econômica, como o PIB municipal e o valor da produção agrícola e pecuária. Quanto maiores os indicadores, melhor o desempenho do município na dimensão econômica.

A avaliação da sustentabilidade dos municípios em relação à dimensão ambiental buscou o foco na utilização e contaminação dos recursos hídricos. Foram utilizados critérios que expressassem indiretamente os impactos causados pela inserção de fármacos no ambiente aquático, decorrente de atividades econômicas ou serviços.

Neste contexto, foram adotados os seguintes critérios para estimar o consumo de água e a inserção destas substâncias nos recursos hídricos: população residente, quantidade de estabelecimentos hospitalares, de pacientes oncológicos atendidos pelo SUS e de cabeças de gado. Também foram considerados a extensão da área cultivada e o índice de esgoto tratado. Quanto maiores os 5 primeiros e menor o último, pior será o desempenho na dimensão ambiental.

As fontes para obtenção dos dados referentes aos critérios escolhidos foram o Sistema Nacional de Informações de Saneamento (SNIS), o Instituto Brasileiro de Geografia e Estatística (IBGE) e o Departamento de Informática do Sistema único de Saúde (DATASUS).

Os critérios que envolvem saneamento foram extraídos da base do SNIS (SNIS, 2016) e os escolhidos para a composição da matriz de decisão e suas definições estão descritos na Tabela 2.

Tabela 2: Critérios do SNIS adotados para a composição da matriz de decisão e suas definições

\begin{tabular}{llcc}
\hline \multicolumn{1}{c}{ CRITÉRIO } & DEFINIÇÃO/FÓRMULA & UNIDADE & FONTE \\
\hline $\begin{array}{l}\text { Índice de Atendimento Total } \\
\text { de Água }\end{array}$ & (População Total Atendida com Água Potável / População Total) X 100 & Percentual & SNIS \\
$\begin{array}{l}\text { Índice de Atendimento Total } \\
\text { de Esgoto }\end{array}$ & (População Total Atendida por Esgotamento Sanitário / População Total) X 100 & Percentual & SNIS \\
Índice de Esgoto Tratado & (Volume de Esgoto Tratado/Volume de Água consumida) X 100 & Percentual & SNIS \\
\hline
\end{tabular}

Revista Verde, v.12, n.4, p.717-728, 2017 
SNIS: Sistema Nacional de Saneamento

O SNIS se constitui na melhor e maior fonte para obtenção de informações sobre saneamento no Brasil, embora alguns dados possam estar comprometidos em função da metodologia de obtenção (COSTA et al., 2013).

Outra fonte de dados consultada e utilizada como base para as ações governamentais é o IBGE-Cidades. Trata-se de uma ferramenta para obter informações sobre todos os municípios do Brasil num mesmo lugar e onde podem ser encontrados gráficos, tabelas, históricos e mapas que traçam um perfil completo de cada uma das cidades brasileiras (IBGE, 2016). Os critérios econômicos e sociais escolhidos para a composição da matriz de decisão, as suas definições e as fontes de obtenção dos respectivos dados estão descritos na tabela 3 .

Tabela 3: Critérios do IBGE adotados para a composição da matriz de decisão e suas definições

\begin{tabular}{|c|c|c|c|}
\hline CRITÉRIO & DEFINIÇÃO/FÓRMULA & UNIDADE & FONTE \\
\hline $\begin{array}{lll}\text { Taxa de } & \text { Mortalidade } \\
\text { Infantil } & & \end{array}$ & $\begin{array}{l}\text { Total de óbitos infantis (menores de um ano) / Total de nascidos } \\
\text { vivos }\end{array}$ & 1000 crianças & IBGE \\
\hline Renda Média & Média da Soma do Rendimento Mensal da População & Salários mínimos & IBGE \\
\hline Taxa de atividade & (População ocupada / População total) X 100 & percentual & IBGE \\
\hline PIB & Total da riqueza produzida pelo município & $\mathrm{R} \$ 1.000 .000 .000,00$ & IBGE \\
\hline Produção Pecuária & Valor da produção pecuária municipal & $\mathrm{R} \$ 1000.000,00$ & IBGE \\
\hline Produção Agrícola & Valor da produção agrícola municipal & $\mathrm{R} \$ 1000.000,00$ & IBGE \\
\hline Área Cultivada & Área do município destinada à produção agrícola & 1000 ha & IBGE \\
\hline Rebanho Bovino & Efetivo de cabeças de gado criadas no município & 1000 cabeças & IBGE \\
\hline População & Total populacional do município & 100.000 habitantes & IBGE \\
\hline
\end{tabular}

IBGE: Instituto Nacional de Geografia e Estatística; PIB: Produto Interno Bruto

As informações sobre assistência à saúde de cada município foram coletadas no sistema DATASUS que mantém uma base de dados nacional necessária ao processo de planejamento, operação e controle do SUS. A base disponibiliza dados sobre a rede hospitalar municipal, a mortalidade referente aos atendimentos hospitalares no SUS e os procedimentos executados. Em relação ao tratamento oncológico, o sistema não especifica quais são esses procedimentos que, a nível ambulatorial, podem ser pequena cirurgia, consulta, quimioterapia, radioterapia ou tratamento paliativo (DATASUS, 2016). Os critérios econômicos e sociais escolhidos para a composição da matriz de decisão, as suas definições e as fontes de obtenção dos respectivos dados estão descritos na Tabela 6.

Tabela 4: Critérios do DATASUS adotados para a composição da matriz de decisão e suas definições

\begin{tabular}{llllcc}
\hline \multicolumn{1}{c}{ CRITÉRIO } & \multicolumn{1}{c}{ DEFINIÇÃO/FÓRMULA } & UNIDADE \\
\hline Índice de Atendimento Hospitalar & $\begin{array}{l}\text { Total de Unidades Hospitalares do Município } \\
\text { Habitantes }\end{array}$ & 10.000 & Unid./10.000 hab. & DATASUS \\
Quantidade de hospitais & $\begin{array}{l}\text { Total de estabelecimentos hospitalares em funcionamento no } \\
\text { município }\end{array}$ & Unidades & DATASUS \\
Total de Pacientes Oncológicos & $\begin{array}{l}\text { Total de pacientes atendidos pelas unidades de oncologia do } \\
\text { Atendidos }\end{array}$ & $\begin{array}{l}\text { SUS no município } \\
\text { Taxa de Mortalidade por }\end{array}$ & (Quantidade de óbitos / número de atendimentos nos hospitais do & Percentual & DATASUS \\
Atendimento Hospitalar & SUS) X 100 & & DATAS \\
\hline
\end{tabular}

DATASUS: Departamento de Informática do Sistema Único de Saúde; SUS: Sistema Único de Saúde

Em relação à estrutura matricial de alternativas e critérios foi escolhido um método multicritério que permita estabelecer um ranking de sustentabilidade entre os municípios avaliados a partir de diversos critérios nas três dimensões do TBL (ALMEIDA, 2013).

Os métodos de apoio multicritério à decisão (MCDA) podem ser definidos como um conjunto de técnicas cuja finalidade é investigar um número de alternativas, considerando múltiplos critérios e objetivos em conflito. Suas principais vantagens são a construção de uma base para o diálogo entre os intervenientes utilizando diversos pontos de vista comuns. Têm a facilidade de incorporar incertezas aos dados e interpretar cada alternativa como um compromisso entre objetivos em conflito, visto que raramente será encontrada uma situação em que exista uma alternativa superior às restantes sobre todos os pontos de vista (LOPES; COSTA, 2007).

Neste trabalho, a imprecisão dos dados e a incerteza do contexto motivaram a utilização do CPP, um método que se destina à ordenação de alternativas com base na teoria de probabilidades. O método foi proposto por Sant'Anna et al. (2013), recebendo desde então as mais diversas aplicações em apoio à decisão. Em especial, cabe destacar as aplicações similares com a ordenação de países e unidades da federação, em diferentes tipos de problemas.

De maneira geral, o método se baseia na ideia-chave da imprecisão dos dados que compõem a matriz de decisão de um problema. Dessa forma, a avaliação da preferência de uma alternativa pode assumir a forma de uma probabilidade dessa alternativa ser escolhida diante das demais. Essa imprecisão pode decorrer de diferentes processos que envolvem avaliações de especialistas, de medidas de desempenho imprecisas, de processos com sistemas métricos imperfeitos, dentre outros que envolvem avaliações humanas em situação de incerteza. (SANT'ANNA et al. 2013; SANT'ANNA 2015; GAVIÃO et al, 2016)

$\mathrm{O}$ método se desenvolve em três estágios. O primeiro se refere à aleatorização das avaliações, que consiste em associar os valores exatos das medidas de preferência a distribuições de probabilidade. Em síntese, um dado é assumido como uma medida de posição em uma distribuição de probabilidades, que reflete a imprecisão do problema em análise. (SANT'ANNA, 2015) 
No segundo estágio do CPP aplicado ao problema, foram calculadas as probabilidades conjuntas de máxima preferência (Max) de cada alternativa "i" em relação às demais, para cada critério “j”. Por convenção, as i-ésimas alternativas variam de um a "m", enquanto os j-ésimos critérios variam de um a "n". A notação matemática do cálculo de Max, para a alternativa Xi, está descrita na Equação (1).

$$
\operatorname{Max} X_{i}=\int_{\Omega_{X_{i}}}\left[\prod F_{X_{-i}}\left(x_{-i}\right)\right] f_{X_{i}}\left(x_{i}\right) d x_{i}
$$

$\mathrm{Na}$ Equação (1), F e f representam respectivamente a função distribuição cumulativa (cdf) e função densidade de probabilidade, atribuídas às alternativas X. A notação “-i”" indica as demais alternativas sob o mesmo critério, à exceção da alternativa considerada no cálculo (i.e i-ésima alternativa). A integração é efetuada no domínio “ $\Omega$ " da i-ésima alternativa (SANT'ANNA et al., 2013).

$$
\begin{aligned}
& P P_{i}=\prod \operatorname{Max}_{i j} \\
& P O_{i}=1-\prod\left(1-\operatorname{Max}_{i j}\right)
\end{aligned}
$$

No terceiro estágio do CPP, efetua-se a composição das probabilidades "Max" em escore de preferência global, para diferentes pontos de vista do decisor. Esses pontos de vista são estimativas descritas a partir de um eixo progressista $(\mathrm{P})$ conservador $(\mathrm{C})$ e um eixo otimista $(\mathrm{O})$ - pessimista $(\mathrm{P})$. Com as probabilidades "Max", é possível definir duas combinações possíveis: os pontos de vista PP ou PO. O ponto de vista PP considera o melhor desempenho das alternativas em todos os critérios. O escore final das alternativas é obtido com o produto das probabilidades de maximizar as preferências, conforme a Equação (2). O ponto de vista $\mathrm{PO}$ apresenta uma decisão mais benevolente, aceitando alternativas com ótimo desempenho em poucos critérios. O escore final desse ponto de vista é obtido pelo complemento do produto das probabilidades não receberem a máxima preferência, conforme a Equação (3).

Tendo em vista a necessidade de orientar a escolha aos Municípios com o melhor desempenho em cada dimensão e conjuntamente na perspectiva do TBL, o ponto de vista PP se mostra mais aderente ao apoio à decisão, sendo assim utilizado para a modelagem do problema de pesquisa.

\section{RESULTADOS E DISCUSSÃO}

Os dados coletados de cada município segundo os critérios escolhidos foram inseridos nas matrizes de decisão das dimensões social, econômica e ambiental. A matriz de decisão da dimensão social está representada na tabela 5.

Os dados coletados nos critérios da dimensão social não permitem inferir qual município obtém o melhor desempenho em toda a dimensão. Os municípios alternam posições superiores, inferiores ou intermediárias nos diferentes critérios.

Estas diferentes posições para um mesmo município nos diferentes critérios consistem no principal argumento a favor do uso de um método MCDA, de forma a obter a ordenação dos municípios segundo o conjunto de critérios.

\begin{tabular}{|c|c|c|c|c|c|}
\hline \multirow{3}{*}{ MUNICÍPIO } & \multicolumn{5}{|c|}{ CRITÉRIOS } \\
\hline & \multicolumn{5}{|c|}{ DIMENSÃO SOCIAL } \\
\hline & 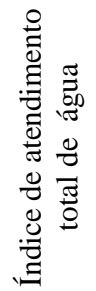 & 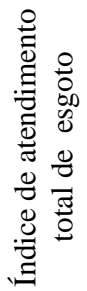 & 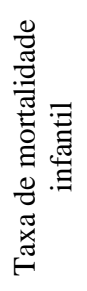 & 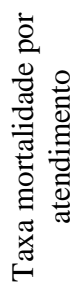 & 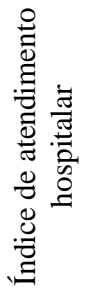 \\
\hline Feira de Santana & 89,96 & 49,41 & 16,83 & 3,35 & 0,46 \\
\hline Itabuna & 98,83 & 69,25 & 19,94 & 6,92 & 0,49 \\
\hline Juazeiro & 93,97 & 59,77 & 17,61 & 6,23 & 0,48 \\
\hline Teixeira de Freitas & 78,74 & 12,62 & 13,36 & 5,05 & 0,37 \\
\hline Vitória da Conquista & 97,82 & 69,20 & 17,64 & 3,91 & 0,52 \\
\hline Arapiraca & 43,89 & 15,65 & 14,77 & 4,50 & 0,34 \\
\hline Caruaru & 95,24 & 41,24 & 13,25 & 4,87 & 0,33 \\
\hline Garanhuns & 95,50 & 8,79 & 12,83 & 5,60 & 0,52 \\
\hline Petrolina & 82,43 & 57,60 & 17,37 & 3,99 & 0,32 \\
\hline Campina Grande & 97,71 & 82,16 & 14,08 & 4,90 & 0,50 \\
\hline Barbalha & 62,83 & 18,97 & 16,89 & 4,73 & 0,52 \\
\hline Sobral & 100,00 & 77,94 & 15,71 & 6,07 & 0,33 \\
\hline Imperatriz & 88,68 & 25,18 & 11,51 & 6,04 & 0,36 \\
\hline Teresina & 94,44 & 18,02 & 15,65 & 5,38 & 0,44 \\
\hline Mossoró & 90,93 & 40,15 & 14,22 & 5,03 & 0,40 \\
\hline
\end{tabular}

Tabela 5. Matriz de decisão com a base de dados da dimensão social para municípios do Nordeste do Brasil

Além disso, os critérios não têm correlação entre si, ou seja, um melhor resultado em um indicador de saúde ou de saneamento, não implica no mesmo desempenho em outro. Esta independência entre os critérios se constitui numa premissa para a aplicação do método escolhido.

Assim, o município com melhor desempenho global representa uma solução satisfatória ao problema de pesquisa, ao invés de significar uma solução ótima.

A matriz de decisão da dimensão econômica está representada na tabela 6 .

\begin{tabular}{|c|c|c|c|c|c|}
\hline \multirow[b]{2}{*}{ MUNICÍPIO } & \multicolumn{4}{|c|}{ CRITÉRIOS } & \\
\hline & $\begin{array}{l}\stackrel{0}{0} \\
\stackrel{0}{\mathscr{2}}\end{array}$ & 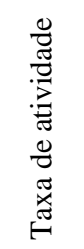 & $\stackrel{\vartheta}{a}$ & 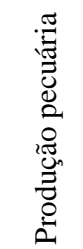 & 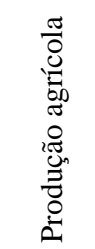 \\
\hline Feira de Santana & 2,05 & 23,60 & $\overline{9,96}$ & 14,86 & 12,69 \\
\hline Itabuna & 2,20 & 21,83 & 2,72 & 4,00 & 17,30 \\
\hline Juazeiro & 2,15 & 16,78 & 2,45 & 2,47 & 355,91 \\
\hline Teixeira de Freitas & 1,95 & 18,61 & 1,67 & 9,90 & 71,07 \\
\hline Vitória da Conquista & 2,00 & 22,58 & 4,66 & 16,72 & 54,32 \\
\hline Arapiraca & 1,70 & 16,47 & 2,82 & 55,58 & 29,13 \\
\hline Caruaru & 1,70 & 24,37 & 5,09 & 35,35 & 0,92 \\
\hline Garanhuns & 1,95 & 15,46 & 1,63 & 13,49 & 7,50 \\
\hline Petrolina & 2,10 & 20,44 & 4,51 & 4,76 & 641,52 \\
\hline Campina Grande & 2,25 & 26,51 & 6,52 & 6,90 & 3,74 \\
\hline Barbalha & 1,65 & 16,36 & 0,61 & 4,93 & 8,96 \\
\hline Sobral & 1,90 & 25,46 & 3,23 & 7,70 & 9,28 \\
\hline Imperatriz & 1,90 & 24,03 & 4,53 & 6,24 & 1,12 \\
\hline
\end{tabular}

Tabela 6. Matriz de decisão com a base de dados da dimensão econômica para municípios do Nordeste do Brasil 


\begin{tabular}{lrrrrr}
\hline Teresina & 2,75 & 35,50 & 14,97 & 10,61 & 21,03 \\
Mossoró & 2,70 & 25,76 & 5,65 & 38,08 & 173,32 \\
\hline
\end{tabular}

Também nesta dimensão, há alternância de posições e independência dos critérios e grau de incerteza, confirmando a ponderação na escolha do método. A matriz de decisão da dimensão ambiental está descrita na tabela 7 .

Tabela 7. Matriz de decisão com a base de dados da dimensão ambiental para municípios do Nordeste do Brasil

\begin{tabular}{|c|c|c|c|c|c|c|}
\hline \multirow[b]{3}{*}{ MUNICÍPIO } & \multicolumn{6}{|c|}{ CRITÉRIOS } \\
\hline & \multicolumn{6}{|c|}{ DIMENSÃO AMBIENTAL } \\
\hline & 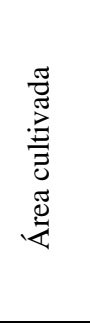 & 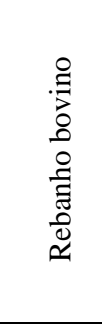 & 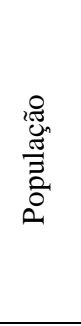 & 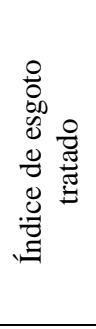 & 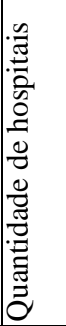 & 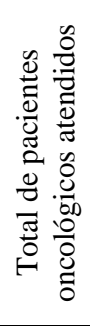 \\
\hline $\begin{array}{l}\text { Feira de } \\
\text { Santana }\end{array}$ & 17,63 & 59,30 & 5,90 & 69,30 & 27 & 49,01 \\
\hline Itabuna & 11,53 & 21,68 & 2,12 & 15,87 & 10 & 97,64 \\
\hline Juazeiro & 32,00 & 15,57 & 2,09 & 30,51 & 10 & 1,10 \\
\hline $\begin{array}{l}\text { Teixeira de } \\
\text { Freitas }\end{array}$ & 6,26 & 85,70 & 1,49 & 14,18 & 5 & 2,37 \\
\hline $\begin{array}{l}\text { Vitória da } \\
\text { Conquista }\end{array}$ & 13,43 & 126,83 & 3,27 & 71,91 & 17 & 68,98 \\
\hline Arapiraca & 11,91 & 30,43 & 2,24 & 0,00 & 7 & 22,87 \\
\hline Caruaru & 2,16 & 27,69 & 3,33 & 43,61 & 11 & 91,11 \\
\hline Garanhuns & 2,97 & 31,14 & 1,34 & 7,09 & 7 & 1,91 \\
\hline Petrolina & 28,68 & 19,85 & 3,16 & 52,75 & 10 & 14,15 \\
\hline $\begin{array}{l}\text { Campina } \\
\text { Grande }\end{array}$ & 6,08 & 18,77 & 3,96 & 83,00 & 20 & 50,06 \\
\hline Barbalha & 2,28 & 8 & 0,57 & 10,65 & 3 & 49,4 \\
\hline Sobral & 14,64 & 40,75 & 1,96 & 48,20 & 6 & 28,0 \\
\hline Imperatriz & 0,61 & 84,48 & 2,51 & 63,65 & 9 & 3,04 \\
\hline Teres & 7,21 & 11,55 & 8,33 & 15,84 & 37 & 165 \\
\hline Mossoró & 24,34 & 22,88 & 2,76 & 36,69 & 11 & 28,1 \\
\hline
\end{tabular}

A avaliação da sustentabilidade dos municípios nas três dimensões se constitui num complexo sistema de critérios em que cada um contribui de modo distinto para a avaliação final. A sustentabilidade em cada dimensão depende do desempenho nos critérios escolhidos, porém, na perspectiva do TBL, percebe-se que tais critérios podem parecer conflitantes quando o atendimento aos objetivos do desenvolvimento sustentável numa determinada dimensão implica num efeito negativo que reduz o desempenho em outra dimensão.

Os municípios de Petrolina e Juazeiro, por exemplo, exibem os maiores valores de produção agrícola entre todos os municípios avaliados (Tabela 6), porém, as áreas cultivadas de ambos (Tabela 7) também são as maiores. Enquanto estes municípios se posicionam como primeiro e segundos no desempenho do critério produção agrícola na dimensão econômica, ambos são os dois últimos colocados segundo o critério de área cultivada na dimensão ambiental. Este exemplo demonstra o conflito entre os critérios, pois a maior produção agrícola melhora o desempenho econômico, porém, contribui para o aumento da área cultivada que necessita de água para irrigação, comprometendo o desempenho ambiental.

Este exemplo também configura um argumento a favor do uso de um método MCDA, de forma a avaliar o conjunto de critérios em função dos possíveis conflitos, níveis de incerteza e independência entre os indicadores adotados e estabelecer uma ordenação que expresse o desempenho global de cada um dos municípios.

Os resultados da ordenação na dimensão social pelo CPP estão descritos na tabela 8.

Tabela 8. Ordenação pela dimensão social de municípios do Nordeste do Brasil

\begin{tabular}{lcc}
\hline MUNICÍPIO & SOC (PP) & SOC Rank \\
\hline Campina Grande & $9,779 \mathrm{E}-06$ & 1 \\
Garanhuns & $1,182 \mathrm{E}-06$ & 3 \\
Mossoró & $8,785 \mathrm{E}-08$ & 10 \\
Barbalha & $7,603 \mathrm{E}-08$ & 11 \\
Imperatriz & $9,577 \mathrm{E}-08$ & 9 \\
Vitória da Conquista & $8,184 \mathrm{E}-06$ & 2 \\
Sobral & $3,951 \mathrm{E}-07$ & 6 \\
Teresina & $6,875 \mathrm{E}-08$ & 12 \\
Juazeiro & $1,852 \mathrm{E}-07$ & 7 \\
Petrolina & $5,521 \mathrm{E}-08$ & 13 \\
Caruaru & $1,666 \mathrm{E}-07$ & 8 \\
Itabuna & $4,528 \mathrm{E}-07$ & 5 \\
Feira de Santana & $6,214 \mathrm{E}-07$ & 4 \\
Teixeira de Freitas & $2,542 \mathrm{E}-08$ & 14 \\
Arapiraca & $6,911 \mathrm{E}-09$ & 15 \\
\hline
\end{tabular}

Observando-se os resultados na dimensão social (Tabela 8), verifica-se que Campina Grande obteve a maior pontuação (9,779E-06), 1,19 vezes o segundo colocado, Vitória da Conquista $(8,184 \mathrm{E}-06)$ e 8,27 vezes mais do que o terceiro, Garanhuns (1,182E-06). Como o CPP é um método não linear, a diferença entre os escores do primeiro para o segundo colocado é maior do que a do segundo para o terceiro e assim por diante, até a menor diferença (3,68 vezes) entre o penúltimo, Teixeira de Freitas (2,542E-08) e Arapiraca, o município de menor score $(6,911 \mathrm{E}-09)$ entre os quinze municípios estudados.

Essas diferenças não lineares beneficiam os municípios com ótimas classificações em um ou dois critérios como, por exemplo, Campina Grande. De acordo com a tabela 5, o município liderou no critério "atendimento de esgoto", foi o quarto no "índice de atendimento hospitalar" e também em "atendimento de água" embora tenha sido o quinto no critério "taxa de mortalidade infantil" e o sétimo em "taxa de mortalidade por atendimento hospitalar".

Outro exemplo é Garanhuns que, embora tenha sido o pior colocado no critério "atendimento de esgoto" e o $11^{\circ} \mathrm{em}$ "taxa de mortalidade infantil" (Tabela 5), foi o segundo colocado no ranking social (Tabela 8) em função da segunda colocação nos critérios "índice de atendimento hospitalar" e "taxa de mortalidade infantil" (Tabela 5).

Por outro lado, Arapiraca que obteve a última colocação no ranking social (Tabela 8), somente se posicionou nas primeiras colocações em um único critério, "taxa de mortalidade por atendimento hospitalar" onde obteve a $4^{\mathrm{a}}$ posição. Foi o último colocado em "atendimento de água", $13^{\circ}$ em "atendimento de esgoto", $12^{\circ} \mathrm{em}$ "atendimento hospitalar" e, embora tenha sido o sétimo no critério "mortalidade infantil", foi superado pelos demais municípios (Tabela 5).

Na dimensão social (Tabela 5), observa-se que, dos 15 municípios avaliados, somente três apresentaram um desempenho no critério "atendimento total de água potável" inferior a $80 \%$. Destes, o município de Teixeira de Freitas apresentou um índice muito próximo, de 78,74\%. Apenas os 
municípios de Arapiraca (43,89\%) e Barbalha (62,83\%) apresentaram índices que demonstram um atendimento de água potável que contempla cerca da metade da população. Tais resultados mostram que os municípios avaliados se encontram em situação mais confortável do que a maioria da região que, de acordo com Medeiros et al. (2016), sofre com uma escassez histórica de água resultante da variabilidade temporal da precipitação, da sua distribuição irregular e também das mudanças climáticas. Tal diferença decorre da posição geográfica dos municípios avaliados onde alguns estão localizados em áreas de maior frequência de precipitações ou próximos de bacias hidrográficas que favorecem a captação. Outra causa pode ser o nível de investimento dos governos municipais e estaduais em saneamento básico.

$\mathrm{Na}$ mesma dimensão, observa-se que o atendimento de água potável é bem superior ao atendimento de esgoto. Dos 15 municípios (Tabela 5), dois apresentam um desempenho no critério "índice de atendimento total de esgoto" inferior a $15 \%$. Em Garanhuns, município que apresentou o pior índice $(8,79 \%)$ o atendimento de água $(95,50 \%)$ é dez vezes maior do que o de esgoto, porém, o município de Campina Grande que apresentou o melhor desempenho $(82,16 \%)$ ainda está distante de alcançar o pleno acesso de seus habitantes ao esgotamento sanitário.

$\mathrm{O}$ acesso insuficiente ao esgotamento sanitário indica que não há uma preocupação em termos de saúde pública com os impactos que a falta da coleta de esgoto pode causar à população, principalmente no que se refere ao desenvolvimento de doenças. A ausência de um esgotamento sanitário adequado nos municípios analisados contraria o estabelecido pela ONU de que o saneamento é uma condição indispensável para saúde humana e que o foco mundial deve ser o alcance ao acesso universal e equitativo ao esgoto coletado e tratado.

Os valores observados para o critério "taxa de mortalidade infantil" (Tabela 5), indicam que apenas o município de Imperatriz apresentou uma taxa $(11,51)$ inferior ao objetivo do desenvolvimento sustentável de reduzir a mortalidade neonatal para pelo menos até 12 por 1.000 nascidos vivos. Seis municípios apresentaram uma taxa inferior a 15 , dois entre 15 e 16 , cinco entre 16 e 18 e o pior resultado $(19,94)$ foi observado no município de Itabuna. Embora as causas da mortalidade infantil estejam associadas a problemas oriundos de falta de esgotamento sanitário adequado, os resultados não indicam uma relação de causa e efeito entre os dois critérios nos municípios avaliados. Observa-se que o pior resultado para o critério "atendimento total de esgoto" foi do município de Garanhuns $(8,79)$ que, entretanto, apresentou o segundo melhor resultado $(12,83)$ para o critério "taxa de mortalidade infantil". Por outro lado, Campina Grande apresentou o melhor índice de atendimento de esgoto $(82,16 \%)$, porém, no critério "taxa de mortalidade infantil" ocupou a quinta posição. Entretanto, tal fato pode ser decorrente, como apontado por Costa et al. (2013), da imprecisão dos dados de saneamento.

O critério "taxa de mortalidade por atendimento hospitalar" (Tabela 5), expressa a razão entre a quantidade de óbitos e o número de atendimentos nos hospitais do SUS pelo local da internação. Este critério está alinhado com o objetivo do desenvolvimento sustentável de atingir o acesso a serviços de saúde essenciais de qualidade embora não exista uma meta definida nos ODS. O município de Feira de Santana apresentou a menor taxa $(3,35)$, seguido de Vitória da Conquista com 3,91. Oito municípios apresentaram uma taxa média entre 4,0 e 6,04 e em três foram observados resultados entre 6,07 em Sobral, 6,23 em Juazeiro e 6,92 observados em Itabuna.

O último critério avaliado na dimensão social, o "índice de atendimento hospitalar", reflete os objetivos da ODS, também sem meta definida, de atingir a cobertura universal de saúde e aumentar substancialmente o financiamento da saúde nos países em desenvolvimento. $\mathrm{O}$ índice mostra a relação entre o total de estabelecimentos hospitalares, públicos e privados, para cada 100.000 habitantes. Os resultados demonstram que não há uma grande disparidade entre os municípios avaliados com um mínimo de 0,32 e um máximo de 0,52 hospitais/100.000 habitantes (Tabela 5).

Observa-se que o município de Vitória da Conquista apresentou o índice máximo e também obteve o melhor desempenho em relação à "taxa de mortalidade por atendimento hospitalar" (Tabela 5). Tal fato poderia indicar uma relação entre investimento e eficiência na área de saúde municipal, porém, o seu indicador para a "taxa de mortalidade infantil" é o segundo pior embora seja o quarto melhor em atendimento de esgoto.

Este município pode ser tomado como exemplo para corroborar a argumentação de Sant'Anna (2015) de que existe uma subjetividade implícita em qualquer processo de avaliação de medidas de desempenho. Além disso, não existe necessariamente uma correlação entre os critérios avaliados na dimensão social, pois o desempenho de cada um depende de diversos fatores.

Observando-se a tabela 5, os resultados mostram que nenhum município foi considerado melhor em mais de um critério e apenas Itabuna foi o pior em dois critérios.

Comparando o ranking obtido pelo CPP (Tabela 8) com a posição dos municípios na tabela 5 , observa-se que Campina Grande, além de ocupar a primeira posição segundo o critério "índice de atendimento total de esgoto", foi o quarto melhor em "índice de atendimento total de água" e "índice de atendimento hospitalar". Também foi o quinto em "taxa de mortalidade infantil" e o sétimo colocado em "taxa de mortalidade por atendimento hospitalar", estando sempre entre os $50 \%$ melhores.

No outro extremo, de acordo com a tabela 5, Arapiraca esteve entre os quatro piores em três critérios ("atendimento total de água", "atendimento total de esgoto" e "atendimento hospitalar") e, em apenas dois ("mortalidade infantil" e "mortalidade hospitalar"), se posicionou entre os 50\% melhores. Itabuna, embora tenha ocupado a última posição em dois critérios ("atendimento total de esgoto" e "mortalidade infantil"), foi segundo em "atendimento total de água", terceiro em "atendimento total de esgoto" e quinto em "atendimento hospitalar" e no ranking da dimensão social (Tabela 8), ocupou a quinta posição.

Ao calcular as probabilidades conjuntas de cada município receber avaliações superiores e inferiores em relação aos demais, o método se mostrou capaz de estabelecer uma ordenação entre os cinco critérios desta dimensão de modo coerente com os resultados obtidos para cada critério individualmente.

Os resultados da ordenação na dimensão econômica estão descritos na tabela 9 . 
Tabela 9. Ordenação pela dimensão econômica de municípios do Nordeste do Brasil

\begin{tabular}{lcc}
\hline MUNICÍPIO & ECO (PP) & ECO Rank \\
\hline Campina Grande & $3,25 \mathrm{E}-07$ & 6 \\
Garanhuns & $6,10 \mathrm{E}-08$ & 14 \\
Mossoró & $4,83 \mathrm{E}-06$ & 2 \\
Barbalha & $3,51 \mathrm{E}-08$ & 15 \\
Imperatriz & $1,12 \mathrm{E}-07$ & 12 \\
Vitória da Conquista & $1,60 \mathrm{E}-07$ & 9 \\
Sobral & $1,19 \mathrm{E}-07$ & 11 \\
Teresina & $5,07 \mathrm{E}-05$ & 1 \\
Juazeiro & $1,76 \mathrm{E}-07$ & 8 \\
Petrolina & $1,03 \mathrm{E}-06$ & 3 \\
Caruaru & $2,55 \mathrm{E}-07$ & 7 \\
Itabuna & $1,21 \mathrm{E}-07$ & 10 \\
Feira de Santana & $3,62 \mathrm{E}-07$ & 5 \\
Teixeira de Freitas & $7,49 \mathrm{E}-08$ & 13 \\
Arapiraca & $4,51 \mathrm{E}-07$ & 4 \\
\hline
\end{tabular}

Verifica-se que Teresina obteve a maior pontuação (5,072E-05), 10,50 vezes mais que o segundo colocado, Mossoró $(4,832 \mathrm{E}-06)$ e 49,20 vezes mais do que o terceiro, Petrolina (1,031E-06).

Também nesta dimensão a diferença (1,74 vezes) entre os escores do penúltimo, Garanhuns (6,096E-08) e Barbalha, o município de menor score $(3,512 \mathrm{E}-08)$ é muito menor do que a diferença entre os três primeiros municípios estudados (Tabela 9). O perfil das diferenças, maior entre os primeiros colocados e menor entre os últimos, é explicada pela não linearidade do método e confirmada pelo desempenho dos primeiros colocados em alguns critérios de acordo com os dados da tabela 6 .

A líder Teresina foi primeira colocada nos critérios "renda", "taxa de atividade" e "produto interno bruto" (PIB) e a sétima em "produção agrícola" e "produção pecuária". Mossoró, o segundo município mais bem avaliado nesta dimensão, foi segundo colocado em "renda" e "produção pecuária", terceiro em "taxa de atividade" e "produção agrícola" e quarto no PIB. Terceira colocada na dimensão econômica, Petrolina foi primeira em "produção agrícola", sexta em "renda" e oitava no PIB. Embora este município tenha se posicionado em décimo lugar no critério "taxa de atividade" e décimo terceiro em "produção pecuária", sua produção agrícola média ( $\mathrm{R} \$ 641,52$ milhões) é quase o dobro da de Juazeiro ( $\mathrm{R} \$ 355,91$ milhões), a segunda colocada no critério. O posicionamento dos três primeiros colocados nas posições superiores de alguns critérios reforça a não linearidade do método que beneficia os municípios com ótimas classificações em um ou dois critérios (Tabela 6).

De acordo com a tabela 6 , verifica-se que a renda média destes municípios varia entre 1,65 e 2,75 salários mínimos. O objetivo da ODS é até 2030, erradicar a pobreza extrema para todas as pessoas em todos os lugares, atualmente medida como pessoas vivendo com menos de US\$ 1,25 por dia. Embora a menor renda média observada seja quase 10 vezes maior do que o patamar de pobreza extrema definido pela ONU, ainda é uma renda média baixa. De acordo com Kageyama e Hoffman (2006), além da desigualdade ser maior no Nordeste e no Centro-Oeste e menor em São Paulo e no Sul, o rendimento médio no Nordeste é menos da metade de São Paulo. Para Pedroso (2014), isto pode ser influenciado pelo fato de que na região Nordeste predomina a agricultura familiar de subsistência e a pecuária extensiva de baixa produtividade. A renda é um indicador que, de acordo com Kageyama e Hoffman (2006), pode não expressar objetivamente o nível de pobreza, porém, considerando o nível de desigualdade econômica do Brasil e face à escassez de outros indicadores, pode ser utilizada em conjunto dentro da perspectiva do desenvolvimento sustentável.

A taxa de atividade da população, expressa pela razão entre a população ocupada e a população total, reflete a importância da ocupação da população como forma de geração de renda e redução da pobreza. Os objetivos do desenvolvimento sustentável pretendem, até 2030, alcançar o trabalho decente com emprego pleno e produtivo, inclusive para os jovens e as pessoas com deficiência e, até 2020, reduzir substancialmente a proporção de jovens sem emprego. Observando os resultados na tabela 6, verifica-se que, excetuando Teresina que apresentou uma taxa de 35,36\%, o restante dos municípios tem entre 15 a $26 \%$ de sua população ocupada. O resultado corrobora Araújo (2014) no que diz respeito ao crescimento da atividade econômica nas cidades médias da região que obteve a segunda com maior crescimento de vagas formais de trabalho entre 2002 e 2010.

Com relação ao PIB local, nota-se que existe uma grande disparidade entre os resultados obtidos (Tabela 6). Enquanto o município de Teresina apresentou o maior produto interno bruto em torno de 15 bilhões de reais, o de Barbalha foi de cerca de 600 milhões, porém, outros sete municípios têm um PIB próximo a 5 bilhões de reais. Este cenário pode estar associado ao fato ressaltado por Pedroso (2014) de que, apesar da escassez da água e da seca, há a incorporação de novos polos agrícolas que permitem o desenvolvimento econômico. De acordo com Mota et al. (2014) e Silva et al. (2014), o crescimento da atividade econômica é indispensável para a redução da pobreza e melhora da qualidade de vida da população em geral.

Por outro lado, o fato de existirem seis municípios com valores de PIB próximos ou inferiores a três bilhões (Tabela 6), pode ser um indicativo de que, de acordo com Pedroso (2014), o crescimento relacionado à inserção de novas práticas agrícolas não tem se distribuído de forma homogênea entre os municípios. Para o autor, este cenário está diretamente relacionado a fatores como irregularidade e distribuição das precipitações e disponibilidade de água.

Os valores obtidos pela produção pecuária e agrícola são indicativos da importância destas atividades para a economia da região e da segurança alimentar da população. Dentre os objetivos do desenvolvimento sustentável destaca-se a eliminação da fome e a garantia de acesso a alimentos seguros, nutritivos e suficientes a todas as pessoas até 2030, em particular os pobres e pessoas em situações vulneráveis, incluindo crianças. Também pretendem dobrar a produtividade agrícola e a renda dos pequenos produtores de alimentos, entretanto como a agricultura consome cerca de $70 \%$ da água disponível no mundo, esta atividade é fortemente dependente da disponibilidade de água, como destacado por Chaves et al. (2015) e Silva (2016).

Os resultados mostram que em Petrolina e Juazeiro, ambos situados às margens do rio São Francisco, a introdução da fruticultura, fortemente dependente de irrigação, fez com que a produção agrícola tenha um peso muito significativo no produto interno bruto destes municípios. No primeiro, para um PIB de $\mathrm{R} \$ 4,51$ bilhões de reais, a produção agrícola corresponde a $\mathrm{R} \$ 641,52$ milhões, ou seja, 14\% de tudo o que o município produz. No segundo, para um PIB de R\$16,55 
bilhões, a produção agrícola corresponde a R $\$ 355$ milhões, cerca de 2,1\%. Em Teresina, o maior PIB dentre os municípios avaliados, esta participação corresponde a cerca de $0,14 \%$ (Tabela 6).

Com relação à produção pecuária, os municípios que apresentaram os maiores valores foram Arapiraca ( $\mathrm{R} \$ 55,58$ milhões), Caruaru (R \$ 35,35 milhões) e Mossoró ( $\mathrm{R}$ \$ 38,08 milhões). Nos dois primeiros, a atividade representa cerca de $0,7 \%$ do PIB municipal enquanto no terceiro chega a aproximadamente 2\% (Tabela 6). A atividade é importante sob o ponto de vista da segurança alimentar da população e da economia de subsistência. Entretanto, é fortemente dependente da disponibilidade hídrica sendo muito impactada pelo regime de precipitação irregular e pelas mudanças climáticas como destaca Medeiros et al. (2015).

Os critérios escolhidos para avaliação dos municípios na dimensão ambiental buscaram inserir a possibilidade de contaminação dos recursos hídricos, tão importantes para a região, na avaliação da sustentabilidade dos municípios. O objetivo é demonstrar que existem externalidades negativas embutidas em atividades econômicas e na prestação de serviços de saúde que têm impacto sobre a qualidade e a disponibilidade hídrica. Estas atividades são imprescindíveis à geração de renda e emprego, à segurança alimentar e à saúde da população e atendem aos objetivos do desenvolvimento sustentável. Contudo, o seu impacto ambiental é conflitante com outros objetivos como a melhoria da qualidade da água, a redução da poluição, a eliminação de despejos e o aumento da eficiência do uso da água através da gestão integrada dos recursos hídricos em todos os níveis.

Os resultados da ordenação na dimensão ambiental estão descritos na tabela 10 .

Tabela 10. Ordenação pela dimensão ambiental de municípios do Nordeste do Brasil

\begin{tabular}{lrc}
\hline MUNICÍPIO & AMB (PP) & AMB Rank \\
\hline Campina Grande & $3,28 \mathrm{E}-08$ & 5 \\
Garanhuns & $2,23 \mathrm{E}-07$ & 2 \\
Mossoró & $5,08 \mathrm{E}-09$ & 11 \\
Barbalha & $6,44 \mathrm{E}-07$ & 1 \\
Imperatriz & $1,25 \mathrm{E}-07$ & 3 \\
Vitória da Conquista & $7,88 \mathrm{E}-10$ & 13 \\
Sobral & $1,97 \mathrm{E}-08$ & 7 \\
Teresina & $2,47 \mathrm{E}-10$ & 15 \\
Juazeiro & $2,60 \mathrm{E}-08$ & 6 \\
Petrolina & $1,34 \mathrm{E}-08$ & 8 \\
Caruaru & $1,00 \mathrm{E}-08$ & 10 \\
Itabuna & $3,68 \mathrm{E}-09$ & 12 \\
Feira de Santana & $4,92 \mathrm{E}-10$ & 14 \\
Teixeira de Freitas & $4,84 \mathrm{E}-08$ & 4 \\
Arapiraca & $1,24 \mathrm{E}-08$ & 9 \\
\hline
\end{tabular}

Verifica-se na tabela 10 que Barbalha obteve a maior pontuação $(6,444 \mathrm{E}-07), 3,89$ vezes o segundo colocado, Garanhuns $(2,227 \mathrm{E}-07)$ e 5,17 vezes mais do que o terceiro, Imperatriz (1,246E-07). Também nesta dimensão a diferença (1,99 vezes) entre os escores do penúltimo, Feira de Santana (4,916E-10) e Teresina, o município com pior avaliação (2,473E-10) é menor do que a diferença entre os três primeiros municípios estudados. Os resultados da dimensão ambiental foram coerentes com os verificados nas duas primeiras dimensões analisadas com relação à posição dos primeiros colocados nos diferentes critérios confirmando mais uma vez a não linearidade do método.

A líder, Barbalha foi a primeira colocada nos critérios "rebanho bovino", "população" e "quantidade de hospitais", terceira em "área cultivada", décima-terceira em "tratamento de esgoto" e décima em "atendimento de pacientes oncológicos". Garanhuns, a segunda colocada nesta dimensão, foi também segunda em "população" e "atendimento a pacientes oncológicos", sendo a quarta em "área cultivada", a quinta em "quantidade de hospitais", a décima em "rebanho bovino" e a décima-quarta em "tratamento de esgoto" (Tabela 7).

Também os dois municípios com pior avaliação na dimensão ambiental ocuparam as posições inferiores do ranking em mais de um critério. Teresina foi a última colocada em três critérios: população, quantidade de hospitais e pacientes oncológicos atendidos, sendo a décima-primeira em tratamento de esgoto, oitava em área cultivada e segunda em rebanho bovino. Feira de Santana foi a décima-quarta em "população" e "quantidade de hospitais", décima-segunda em "área cultivada" e "rebanho bovino", nona em "pacientes oncológicos atendidos" e terceira em "tratamento de esgotos" (Tabela 7).

A área cultivada está diretamente relacionada ao consumo de água para irrigação, pois, quanto maior a área cultivada, maior será o dispêndio deste recurso. Pelos resultados apresentados, pode-se observar que os dois municípios que apresentam a maior área destinada à agricultura, Juazeiro (32.000 ha) e Petrolina (28.680 ha), também apresentam bons resultados no critério "índice de atendimento total de água", porém, é importante salientar que ambos têm grande disponibilidade hídrica, pois se situam às margens do rio São Francisco. Os demais municípios têm uma área destinada à agricultura variando entre 608 ha em Campina Grande a 24.340 ha em Mossoró, entretanto nem todos dispõem de grandes volumes de recursos hídricos ao longo de todo o ano (Tabela 7). Neste contexto, o cumprimento dos objetivos do desenvolvimento sustentável em relação aos recursos hídricos se torna imprescindível na região, pois como destaca Medeiros et al. (2015) embora a agricultura seja um importante pilar econômico da região Nordeste, o uso continuo de água numa região de escassez hídrica torna indispensável a busca pela sua utilização sustentável.

Outro fator avaliado na dimensão ambiental é o número de cabeças de gado. Os municípios de Teixeira de Freitas (85.700), Imperatriz (84.480) e Vitoria da Conquista (126.830) apresentam grandes rebanhos bovinos (Tabela 7). Apesar da importância da pecuária para a economia de subsistência para o Nordeste, é importante destacar que os rebanhos, para garantir a sanidade, recebem diversos medicamentos que podem ocasionar consideráveis problemas ambientais uma vez que os resíduos destes fármacos são inseridos no solo e atingem os cursos d'água. Como os tratamentos de água convencionais são incapazes de remover os fármacos do meio aquático, como aponta Silva (2016), a qualidade da água de reuso para irrigação e outras atividades pode ser afetada. Este quadro pode comprometer uma alternativa que vem se mostrando importante para atenuar a escassez de água na região como apontam Silva et al. (2014), Barros (2015), Medeiros et al. (2015) e Albuquerque Júnior et al. (2016). 
O expressivo crescimento das cidades médias da região Nordeste nos últimos anos embute externalidades ambientais negativas como o crescente consumo de água potável, a consequente geração de esgoto e resíduos sólidos urbanos, a poluição atmosférica e o desmatamento, constituindo um passivo ambiental que é dividido por toda a sociedade. Além destes impactos, quanto maior a população residente de um município, maior será a probabilidade de inserção de resíduos de substâncias químicas através da excreção dos fármacos e da disposição inadequada dos medicamentos não consumidos. Observa-se que, exceto Teresina ( 833.000 habitantes) e Feira de Santana (590.000 habitantes), os demais municípios têm um porte médio, com menos de 400.000 habitantes (Tabela 7). Todos se caracterizam como pólos econômicos regionais associados à geração de emprego e renda e ao aumento da oferta de serviços de saúde. Entretanto, para que o seu crescimento atenda aos objetivos do desenvolvimento sustentável pelos é necessário que haja uma gestão eficiente dos recursos hídricos como destacam Ferreira et al. (2014), Sousa et al. (2014), Andrade et al. (2015) e Chaves et al. (2015).

O índice de esgoto tratado também é um critério para inferir o despejo de substâncias químicas no ambiente, pois quanto menos esgoto se trata, maior o despejo diretamente nos cursos d'água. Este indicador da dimensão ambiental está diretamente relacionado ao anterior. Quanto maior a população, maior a necessidade de coletar e tratar o esgoto gerado, porém, os resultados demonstram que apenas um município, Campina Grande, trata mais de $80 \%$ do esgoto gerado em relação à água consumida. Dois (Feira de Santana e Vitória da Conquista), tem um índice próximo de $70 \%$ e um, Imperatriz, próximo a $60 \%$. Os demais tratam menos de $50 \%$ do esgoto gerado (Tabela 7). O município de Arapiraca demonstra não realizar nenhum tratamento do esgoto, porém, é importante esclarecer que é a informação que consta na base de dados do SNIS.

Esses resultados, além de demonstrar um baixo comprometimento com os objetivos do desenvolvimento sustentável, apontam para a questão do comprometimento da qualidade das águas superficiais, tão importantes numa região de escassez hídrica. O fato adquire maior importância em função de que todos os municípios avaliados se encontram no interior da região e consequentemente outros dependem dos mesmos cursos d'água que sofrem o impacto dos despejos. Neste contexto de escassez, as águas superficiais são captadas para uso na agricultura, pecuária e consumo humano e, como relata Chaves et al. (2015), a gestão consciente e eficiente deste recurso é decisiva no combate à pobreza.

A quantidade de estabelecimentos hospitalares nos municípios reflete o nível de acesso à saúde pela população. Entretanto, está associada a um impacto ambiental que vem preocupando pesquisadores em diversos países: a inserção de resíduos de fármacos no ambiente. Sob o ponto de vista ambiental, uma das consequências de uma maior quantidade de hospitais em um município é o aumento da concentração de resíduos de diversos fármacos num só local que posteriormente pode ser inserido nas águas residuárias. Como a legislação brasileira não determina que as organizações de saúde sejam obrigadas a realizar um pré-tratamento de seus efluentes, a rede de esgotos do município acaba por receber esta carga. (GALLO et al., 2012; MOURA et al., 2015; KUMMERER et al., 2016; SILVA, 2016).
Pelos resultados do índice de esgoto tratado encontrados neste trabalho, mesmo que o efluente da unidade hospitalar seja coletado, há uma grande possibilidade de não ser tratado. Neste contexto, quanto mais unidades hospitalares houver num município (Tabela 7), como por exemplo, em Teresina (37), Feira de Santana (27), Campina Grande (20) e Vitória da Conquista (17), maior será a possibilidade de inserção de resíduos de fármacos no ambiente aquático do que em municípios como Barbalha (3) e Teixeira de Freitas (5).

Outro critério relacionado à inserção de resíduos de fármacos no ambiente é o atendimento a pacientes oncológicos pelo SUS, disponibilizado em estabelecimentos de saúde habilitados como referência, distribuídos pelos estados numa proporção de 1 (um) estabelecimento de saúde para cada 500.000 (quinhentos mil) habitantes. Esta política centraliza os atendimentos de maior complexidade como a quimioterapia em determinados municípios que atendem às populações de cidades no seu entorno. Neste contexto, os medicamentos que são de uso restrito às unidades que prestam este tipo de atendimento, são administrados aos pacientes oncológicos e, na maioria dos casos, seus resíduos são em parte excretados na própria unidade hospitalar. Consequentemente, a quantidade de pacientes oncológicos atendidos num município concentra resíduos de uma classe de fármacos potencialmente perigosos a serem lançados na rede de esgoto ou diretamente no ambiente.

Observa-se na tabela 7 que Teresina e Itabuna já atendem mais de 100 mil pacientes por ano e tratam somente cerca de $15 \%$ do esgoto gerado. Apenas 4 municípios apresentam um número de pacientes oncológicos atendidos inferior a 10.000 indivíduos por ano. Este cenário indica uma possibilidade real de inserção de resíduos de fármacos antineoplásicos nas águas superficiais, o que corrobora a preocupação dos autores Booker et al. (2014), Parrella et al. (2014), Moura et. al. (2015) e Kümmerer et al. (2016).

Após a ordenação quanto aos critérios propostos nas dimensões social, econômica e ambiental, foi estabelecido um ranking dos municípios pela perspectiva do TBL, considerando o desempenho de cada um em todos os critérios simultaneamente. O resultado está apresentado na tabela 11.

Tabela 11. Ordenação pela perspectiva do Triple Bottom Line (TBL) de municípios do Nordeste do Brasil

\begin{tabular}{lcc}
\hline MUNICÍPIO & TBL $($ PP) & TBL rank \\
\hline Campina Grande & $1,04 \mathrm{E}-19$ & 1 \\
Garanhuns & $1,61 \mathrm{E}-20$ & 2 \\
Mossoró & $2,16 \mathrm{E}-21$ & 3 \\
Barbalha & $1,72 \mathrm{E}-21$ & 4 \\
Imperatriz & $1,33 \mathrm{E}-21$ & 5 \\
Vitória da Conquista & $1,03 \mathrm{E}-21$ & 6 \\
Sobral & $9,27 \mathrm{E}-22$ & 7 \\
Teresina & $8,62 \mathrm{E}-22$ & 8 \\
Juazeiro & $8,46 \mathrm{E}-22$ & 9 \\
Petrolina & $7,60 \mathrm{E}-22$ & 10 \\
Caruaru & $4,27 \mathrm{E}-22$ & 11 \\
Itabuna & $2,02 \mathrm{E}-22$ & 12 \\
Feira de Santana & $1,11 \mathrm{E}-22$ & 13 \\
Teixeira de Freitas & $9,22 \mathrm{E}-23$ & 14 \\
Arapiraca & $3,863 \mathrm{E}-23$ & 15 \\
\hline
\end{tabular}

Observando o ranking final segundo o TBL (Tabela 11), verifica-se que Campina Grande ocupou o primeiro lugar entre os municípios estudados. O município foi o mais bem avaliado na dimensão social, quinto colocado na dimensão 
ambiental e sexto na econômica. Quando se analisa o desempenho médio em todos os critérios (tabelas 5, 6 e 7), este município se colocou entre as 4 primeiras posições em 8 critérios, sendo primeiro em dois. Observando-se as posições inferiores, percebe-se que Campina Grande não ocupou a última posição em nenhum critério e apenas em 3, se posicionou entre as 4 últimas posições. O resultado confirma a premissa do método CPP de considerar o melhor desempenho das alternativas em todos os critérios e obter um escore final das alternativas beneficiando os municípios com ótimas classificações em um ou dois critérios.

A colocação final dos municípios de Teresina e Barbalha pode exemplificar a complexidade da avaliação da sustentabilidade na perspectiva do TBL. A sustentabilidade em cada dimensão depende do desempenho nos critérios escolhidos e eles podem ser conflitantes quando o atendimento aos objetivos do desenvolvimento sustentável numa determinada dimensão implica num efeito negativo que reduz o desempenho em outra dimensão. Estes municípios foram os primeiros colocados em duas dimensões (econômica e ambiental respectivamente), porém, ocuparam a última e penúltima colocação em outras duas (ambiental e econômica respectivamente). Na perspectiva do TBL, Teresina foi a oitava colocada e Barbalha a quarta. Embora tenha apresentado indicadores econômicos robustos para a região, o município de Teresina ocupou a última posição em três dos seis indicadores da dimensão ambiental. O município de Barbalha apresentou os piores indicadores econômicos, porém, só ocupou a última posição em dois critérios. Ambos ocuparam a primeira colocação em dois critérios, porém, Barbalha se colocou entre os quatro melhores em cinco critérios e Teresina em quatro. Como o método considera o melhor desempenho das alternativas em todos os critérios, estas diferenças influenciaram o desempenho final onde Barbalha se posicionou quatro posições acima de Teresina.

\section{CONCLUSÃO}

As ações alinhadas aos objetivos do desenvolvimento sustentável são heterogeneamente implementadas nos municípios do Nordeste do Brasil. Enquanto alguns exibem um desempenho robusto com relação ao desenvolvimento econômico outros ainda se mantém distantes das metas de redução da pobreza. Sob a perspectiva social existe uma disparidade na implantação de serviços básicos, principalmente o saneamento. Com relação à dimensão ambiental, se expressa os impactos negativos que diferentes atividades econômicas ou serviços públicos podem causar nos recursos hídricos que são historicamente escassos na região e apontando, dentre os municípios avaliados, aqueles mais suscetíveis ao comprometimento da qualidade das suas águas superficiais.

Sob a perspectiva do Triple Bottom Line mostrou que o bom desempenho em apenas uma dimensão não é suficiente para expressar a sustentabilidade do município, reforçando a importância da abordagem do desenvolvimento sustentável na incorporação do bem-estar humano e na utilização responsável dos recursos naturais ao desenvolvimento econômico.

\section{REFERÊNCIAS}

ALBUQUERQUE JÚNIOR, J.; AZEVERDO, C.; AZEVEDO, M.; FRANÇA, J.; MONTEIRO FILHO, A. Qualidade de águas residuárias e salobra utilizadas no cultivo hidropônico de três cultivares de alface crespa. Revista Verde de Agroecologia e Desenvolvimento Sustentável, v. 11, n. 2, p. 19-24, 2016.

ALMEIDA, A.T. Processo de Decisão nas Organizações: construindo modelos de decisão multicritério. São Paulo: Editora Atlas, 2013.

ANDRADE, S.; CRISPIM, D.; SOUSA, M.; CHAVES, A.; MARACAJÁ, P. Análise espacial da qualidade microbiológica das águas do rio Piancó no trecho CoremasPombal-PB. Revista Verde de Agroecologia e Desenvolvimento Sustentável, v. 10, n. 2, p. 157-161, 2015.

ARAÚJO, T. Nordeste: desenvolvimento recente e perspectivas. Um olhar territorial para o desenvolvimento: Nordeste. Rio de Janeiro: Banco Nacional de Desenvolvimento Econômico e Social, p. 540-560, 2014.

BANCO MUNDIAL. World Bank National Accounts Data. Disponível em: <https://data.worldbank.org/indicator/NY.GDP.MKTP.CD?vi ew $=$ chart $>$. Acessado em 20/11/2017

BARROS, J. O passado no presente: a visão do economista. In $\mathrm{O}$ mundo rural no Brasil do século 21. A formação de um novo padrão agrário e agrícola. Empresa Brasileira de Pesquisa Agropecuária (EMBRAPA). Brasília, 2014.

BOOKER, V.; HALSALL, C.; LLEWELLYN, N.; JOHNSON, A.; WILLIAMS, R. Prioritising anticancer drugs for environmental monitoring and risk assessment purposes. Science of the Total Environment, v. 473, p.159-170, 2014.

CHAVES, A. D.; ALMEIDA, R. R; CRISPIM, D. L.; SILVA, F. T.; SILVA, E. P. Análises físicas das águas subterrâneas de poços localizados nas comunidades Várzea Comprida dos Oliveiras e Bezerro no município de PombalPB. Revista Verde de Agroecologia e Desenvolvimento Sustentável, v. 10, n. 2, p. 74-78, 2015.

COSTA, S.; CÔRTES, L.; COELHO, T.; FREITAS, M. Indicadores em Saneamento: avaliação da prestação dos serviços de água e de esgoto em Minas Gerais. Rev. UFMG, Belo Horizonte, v. 20, n.2, p. 334-357, 2013.

DATASUS. DEPARTAMENTO DE INFORMÁTICA DO SISTEMA ÚNICO DE SAÚDE. Informações em Saúde (TABNET). Rio de Janeiro: DATASUS, 2016. Disponível em: <http://www2.datasus.gov.br/DATASUS/index.php> Acessado em: 15/04/2017.

FERREIRA, P. M.; QUEIROZ, M. M.; SOUSA, T.M.; GARRIDO, J. W..; COSTA, F. F. Qualidade físico-química da água para irrigação do rio Piancó Piranhas Açu na cidade de Pombal - PB. Revista Verde de Agroecologia e Desenvolvimento Sustentável. v. 9, n.4, p.78-83, 2014. 
GALLO, E.; FARAONI, F. S.; PAIVA, D.M.; MESQUITA, H. M.; BUSS, D. F.; ABREU, F. N.; MARCHIORI, P. Saúde e economia verde: desafios para o desenvolvimento sustentável e erradicação da pobreza. Ciência \& Saúde Coletiva. v. 6, n. 17 p. 1457-1468, 2012.

GAVIÃO, L.; SILVA, R.F; SANT'ANNA, A.P.; LIMA, G.B. Ordenação de municípios por potencial de contaminação de águas com fármacos oncológicos por composição probabilística de preferências. Anais do XLVIII SBPO. Simpósio Brasileiro de Pesquisa Operacional. Vitória, ES, 2016.

IBGE. INSTITUTO BRASILEIRO DE GEOGRAFIA E ESTATISTICA. Diretoria de Pesquisas, Coordenação de População e Indicadores Sociais. IBGE Cidades. Rio de Janeiro: IBGE, 2016. Disponível em: <http://www.cidades.ibge.gov.br/xtras/home.php>. Acessado em: 20/04/2017.

JUNQUEIRA, L; $\quad$ MAIOR, J.; PINHEIRO, F. Sustentabilidade: a produção científica brasileira entre os anos de 2000 e 2009. Revista de Gestão Social e Ambiental. v. 5, n. 3, p. 36-52, 2011.

KAGEYAMA, A.; HOFFMANN, R. Pobreza no Brasil: uma perspectiva multidimensional. Economia e Sociedade, Campinas, v. 15, n. 1 (26), p. 79-112, jan. /jun. 2006.

KÜMMERER, K.; SCHUSTER, A.; HEIN, A.; EBERT, I. Antineoplastic compounds in the environment. Substances of special concern. Environmental Science and Pollution Research, v. 23, n. 15, p. 14791-14804, 2016.

LOPES, Y.; COSTA, A. Modelo de decisão para seleção de sistemas de informação baseado em decisão multicritério e programação inteira 0-1. Revista Gestão Industrial, v. 3, N. 4, p. 135-146, 2007.

MACEDO, M.; FERREIRA, A.; CÍPOLA, F. Análise do nível de sustentabilidade das unidades federativas do Brasil e de suas capitais: um estudo sob as perspectivas econômica, social e ambiental. Revista de Gestão Social e Ambiental. v. 5, n. 3, p. 73-89, 2011

MEDEIROS, A.; NOBRE, R.; SILVA, E; ARAÚJO, W; QUEIROZ, M. Crescimento inicial da berinjeleira sob adubação nitrogenada e fosfatada e irrigada com água de reuso. Revista Verde de Agroecologia e Desenvolvimento Sustentável. v.10, n.3, p. 34-40, 2015.

MOTA, J.; ALMEIDA M.; SILVA, M.; ALENCAR, V. Estudo da complexidade ambiental visando o conhecimento interdisciplinar dos saberes e da educação ambiental. Revista Verde de Agroecologia e Desenvolvimento Sustentável. v.9, n.5, p. 07-11,2014.

MOURA, L.; SILVA, R.; PONTES, A.; SOUZA, R. Avaliação de Riscos Ambientais em Hospitais: aplicação ao tratamento quimioterápico. Revista de Gestão Social e Ambiental, v. 9, n. 1, p. 66-81, jan. /abr., 2015
ONU. Organização das Nações Unidas. Agenda 2030 e os Objetivos de Desenvolvimento Sustentável (ODS), 2016a. Disponível em:< http://www.agenda2030.com.br/aagenda2030.php>. Acessado em: 10/04/2017.

ONU. Organização das Nações Unidas. Human Development Report, 2016b. Disponível em: <http://hdr.undp.org/sites/default/files/2016_human_develop ment_report.pdf> Acessado em: 10/04/2017.

PARRELLA, A.; LAVORGNA, M.; CRISCUOLO, E.; RUSSO, C.; FIUMANO, V.; ISIDORI, M. Acute and chronic toxicity of six anticancer drugs on rotifers and crustaceans. Chemosphere, V. 115, p. 59-66, 2014.

PEDROSO, M. Experiências internacionais com a agricultura familiar e o caso brasileiro $\mathrm{O}$ desafio da nomeação e suas implicações práticas. In O mundo rural no Brasil do século 21. A formação de um novo padrão agrário e agrícola. Empresa Brasileira de Pesquisa Agropecuária (EMBRAPA). Brasília, 2014.

PROQUE, A. Externalidades do setor sucroalcooleiro: inserção de centrais co-geradoras a bagaço de cana. Revista Meio Ambiente e Sustentabilidade. v. 7, n.3, p. 446 - 468, 2014.

SANT'ANNA A. P.; FARIA, F.; COSTA, H. G. Aplicação da Composição Probabilística e do método das K-Médias à classificação de municípios quanto à oferta de creches. Cadernos do IME, Série Estatística. v.34, n. 1, p.17, 2013.

SANT'ANNA A. P. Probabilistic Composition of Preferences, Theory and Applications. New York: Springer, 2015.

SILVA, T.; SANTOS, J.; LOPES, R..; LIMA, V.; MONTEIRO, D. Efeito residual nas características do solo irrigado com água residuária doméstica tratada e adubação orgânica. Revista Verde de Agroecologia e Desenvolvimento Sustentável. v. 9, n.1, p.312-319, 2014.

SILVA, R. Ocorrência de fármacos em ambientes aquáticos: indicadores de saneamento em municípios com unidades de atendimento oncológico. Trabalho de Conclusão de Curso (Especialização em Economia e Meio Ambiente) Universidade Federal do Paraná. Curitiba, 2016.

SNIS. SISTEMA NACIONAL DE INFORMAÇÕES DE SANEAMENTO. Série Histórica. Informações e Indicadores Agregados. Brasília: SNIS, 2016. Disponível em: <http://www.snis.gov.br/aplicacao-web-serie-historica> Acessado em: 25/04/2017.

SOUSA, T.; FERREIRA, P.; GARRIDO, J.; QUEIROZ, M.; SILVA, F. Qualidade ambiental da bacia do rio Piancó Piranhas Açu. Revista Verde de Agroecologia e Desenvolvimento Sustentável. v. 9, n.4, p.84-94, 2014. 